International Journal of Engineering \& Technology, $7(1.2)(2018) 235-238$
International Journal of Engineering \& Technology
Website: www.sciencepubco.com/index.php/IJET
Research paper

\title{
Diagnosis of lesion with statistical method of Anova1 \& two ways for multi-MRI images with format. dicom
}

\author{
Kaouther El Kourd ${ }^{1}$ *, Atianaoual ${ }^{2}$, Abdenour Bouaicha ${ }^{3}$, Souleyman Benkraouda ${ }^{4}$ \\ ${ }^{1}$ Faculty of science,Benyoucef ben khedda (Algiers1) University Algeia \\ ${ }^{2}$ Faculty of science \&engineering, University of Biskra,Algeria \\ ${ }^{3}$ Faculty of science, Benyoucef ben khedda (Algiers1) University, Algeria \\ ${ }^{4}$ Preparatory school of Algiers, Algeria \\ *Corresponding author E-mail: kaouther_youcef@yahoo.fr
}

\begin{abstract}
This paper deals with real time surface detection for image processing and analysis. We propose an appropriate analysis method with analysis of variance two ways to detect all surfaces of images in accuracy time. The results indicate that Anova_2 converged to the solution in accuracy time in comparison with Anova_1 for linear model.
\end{abstract}

Keywords: Anova; 1; Anova 2; Statistical; Regression.

\section{Introduction}

Segmentation means division of an image into several connected regions. Basically, it could define a region as a group of connected similar pixels, or a set of connected pixels surrounded by discontinuities (edges). Split and merge uses the first approach.

Many methods are used in surface detection in image processing and analysis. They are classified under two groups depending on time execution: accuracy time (real-time execution), and nonaccuracy time (non-real-time execution). One of the methods in image detection is the analysis of detection (Anova). Anova is a hypothesis test method. It has two techniques: one-way Anova (Anova_1), two-way Anova (Anova_2).

ANOVA_1 is a hypothesis test in which only one categorical variable or single factor is considered. It is a technique which enables us to make a comparison of means of three or more samples with the help of F-distribution. It is used to find out the difference between its different categories having several possible values.[1-2] The null hypothesis $\left(\mathrm{H}_{0}\right)$ is the equality in all population means, while the alternative hypothesis $\left(\mathrm{H}_{1}\right)$ will be the difference in at least one mean.

Anova_1 is based on the following assumptions:

1) Normal distribution of the population from which the samples are drawn.

2) Measurement of the dependent variable is at interval or ratio level

3) Two or more than two categorical independent groups in an independent variable.

4) Independence of samples.

5) Homogeneity of variance of the population.

Anova_2 is a hypothesis test wherein the classification of data is based on two factors. For instance, the two bases of classification for the sales made by the firm are first as the basis of sales by the different salesman, and second by sales in the various regions. It is a statistical technique used by the researcher to compare several levels of the two independent variables involving multiple observations at each level.

ANOVA examines Two way affected by two factors on the continuous dependent variable. It also studies the inter-relationship between independent variables influencing the values of the dependent variable.[1-2]

- Assumptions of two-way ANOVA:[1-2]

1) Samples are drawn for distribution of population.

2) Measurement of dependent variable at continuous level.

3) Two or more than two categorical independent groups in two factors.

4) Categorical independent groups should have the same size.

5) Independence of observations

6) Homogeneity of the variance of the population

\section{Back ground}

\subsection{ANOVA1 the analysis of variance}

a) Regration analysis of variance

The relationship between two variables is the dependent 'one' and the independent 'operation'. [3-5]

b) Fitted Regretion Line

Equation (1) presents the true regression line which is usually never known. However, the regression line can be estimated where estimating the coefficients $\beta_{1}$ and $\beta_{0}$ for an observed data set. [6-7]

$E(Y)=\beta_{0}+\beta_{1} x$

Equation (2) represents the actual values of $y$ which are assumed to be the sum of the mean value, $\mathrm{E}(\mathrm{Y})$ and a random error term $\varepsilon$.

$\mathrm{Y}=\mathrm{E}(\mathrm{Y})+\mathrm{e}$ 
The least square estimates $\check{\beta}_{1}$ and $\check{\beta}_{0}$, areobtained from using the following equations:

Equations (3), (4) represent the least square estimates $\check{\beta}_{1}$ and $\check{\beta}_{0}$ respectively:

$\check{\beta}_{1}=\frac{\sum_{\mathrm{i}=1}^{\mathrm{n}} \mathrm{y}_{\mathrm{i}} \mathrm{x}_{\mathrm{i}}-\frac{\left(\sum_{\mathrm{i}-1}^{\mathrm{n}} \mathrm{y}_{\mathrm{i}}\right)\left(\sum_{\mathrm{i}-1}^{\mathrm{n}} \mathrm{x}_{\mathrm{i}}\right)}{n}}{\sum_{\mathrm{i}=1}^{\mathrm{n}}\left(\mathrm{x}_{\mathrm{i}}-\overline{\mathrm{x}}\right)^{2}}$

$\tilde{\beta}_{0}=\check{y}-\check{\beta}_{1} \bar{x}$

Where :

$\overline{\mathrm{x}}$ is the mean of all predictor variable calculated using equation (5), and $\tilde{y}$ is the mean of all observed values calculated using equation (6):

$\mathrm{x}=\frac{1}{\mathrm{n}}\left(\sum_{\mathrm{i}=1}^{\mathrm{n}} \mathrm{x}_{\mathrm{i}}\right)$

After know $\breve{\beta}_{1}$ and $\check{\beta}_{0}$, the fitted regression line will be written as:

$\mathrm{y}=\tilde{\beta}_{0}+\tilde{\beta}_{1}$

Where the difference between the corresponding observed value, $\mathrm{y}_{\mathrm{i}}$ and the fitted value, $\overline{\mathrm{y}}_{\mathrm{i}}$ is called the residuale $\mathrm{i}_{\mathrm{i}}$ :

$\mathrm{e}=\mathrm{y}_{\mathrm{i}}-\tilde{y}_{\mathrm{i}}$

c) Calculation of the statistique F0

The statistic $F_{0}$ test the significance of regression is calculated as follows: [6-7]

$\mathrm{F}_{0}=\frac{\mathrm{MS}_{\mathrm{B}}}{\mathrm{MS}_{\mathrm{E}}}$

Where: $M S_{R}$ is the regression mean square and $\mathrm{MS}_{\mathrm{E}}$ is the mean square error.

To calculate the statistic $F_{o}$, it must study the following six models

[3] [4] [5].

C.1 Total Sum of Squares $\left(\mathrm{SS}_{\mathrm{T}}\right)$ model

The $\mathrm{SS}_{\mathrm{T}}$ is obtained using the equation (9):

$\mathrm{SS}_{\mathrm{T}}=\sum_{\mathrm{i}=1}^{\mathrm{n}}\left(\mathrm{y}_{\mathrm{i}}-\tilde{\mathrm{y}}\right)^{2}$

C.2 Sum of Squares regression $\left(\mathrm{SS}_{\mathrm{R}}\right)$ model

The $\mathrm{SS}_{\mathrm{R}}$, can be obtained using the equation (10): [5]

$\mathrm{SS}_{\mathrm{R}}=\sum_{\mathrm{i}=1}^{\mathrm{n}} \tilde{\mathrm{y}}_{\mathrm{i}}^{2}-\frac{\left(\sum_{\mathrm{i}=1}^{\mathrm{n}} \mathrm{y}_{\mathrm{i}}\right)^{2}}{\mathrm{n}}$

C.3 Sum Squares Error (SSE) operation

The $\mathrm{SS}_{\mathrm{E}}$ is obtained using the equation (11):

$\mathrm{SS}_{\mathrm{E}}=\mathrm{SS}_{\mathrm{T}}-\mathrm{SS}_{\mathrm{R}}$

C.4 The total Mean Squares $\left(\mathrm{MS}_{\mathrm{T}}\right)$ model

The $\left(\mathrm{MS}_{\mathrm{T}}\right)$ are obtained by dividing the $\mathrm{SS}_{\mathrm{T}}$ with their associated degrees of freedom. The number of degrees of freedom associated with $\mathrm{SS}_{\mathrm{T}}$ is $\mathrm{n}-1$ since there are an 'n' observations, but one degree of freedom is lost in the calculation of the sample mean $\bar{y}$.

$\mathrm{MS}_{\mathrm{T}}=\frac{\mathrm{SS}_{\mathrm{T}}}{\mathrm{n}-1}$

C.5 The regression mean square $\left(\mathrm{MS}_{\mathrm{R}}\right)$ model

The number of freedom degrees associated with the $\mathrm{SS}_{\mathrm{R}}$, is $\mathrm{k}$. so, There are $k+1$ degrees of freedom associated with a regression model with $\mathrm{k}+1$ coefficients $\beta_{0}, \beta_{1}, . . \beta_{\mathrm{k}}$. However, one degree of freedom is lost because the deviations $\left(\hat{\mathrm{y}}_{\mathrm{i}}-\overline{\mathrm{y}}\right)$, are subjected to the constraints that they must sum to zero $\sum_{\mathrm{i}=1}^{\mathrm{n}}\left(\tilde{y}_{\mathrm{i}}-\overline{\mathrm{y}}\right)^{2}$

The $\mathrm{MS}_{\mathrm{R}}$ is obtained using the equation (13):

$\mathrm{MS}_{\mathrm{R}}=\frac{S S_{\mathrm{R}}}{\mathrm{k}}$

Since there are $\mathrm{n}$ observations in all, the number of degrees of freedom associated with the error sum squares is: $\mathrm{n}-(\mathrm{k}+1)$, but $(\mathrm{k}+1)$ degrees of freedom are lost in obtaining the estimates of $\beta_{0}, \beta_{1}, \beta_{2} \ldots \ldots \beta_{\mathrm{k}}$ to calculate the predicted values $\overline{\mathrm{y}}_{\mathrm{i}}$. [5-7]

C.6. the Mean square Error $\left(\mathrm{MS}_{\mathrm{E}}\right)$ model

The $\mathrm{MS}_{\mathrm{E}}$ is obtained using equation (14)

$\mathrm{MS}_{\mathrm{E}}=\frac{\mathrm{SS}_{\mathrm{E}}}{\mathrm{n}-(\mathrm{k}+1)}$

The $\mathrm{MS}_{\mathrm{E}}$ is an estimated of the variance $(\widetilde{\sigma})^{2}$ of random error terms.

\subsection{Anova 2 two ways}

The ANOVA 2-way is probably the most popular layout in our Design and Experiments. To begin with, we have to define a factorial experiment. [1].

An experiment that uses every combination of factor levels as treatments is called a factorial experiment.

A.1. two-way factorial experiment Model

In a factorial experiment the factor $\mathrm{A}$ at a levels and factor $\mathrm{B}$ at $\mathrm{b}$ levels.

The model for the general layout can be written as:

$y_{i j k}=\mu+\tau_{i}+\beta_{j}+\gamma_{i j}+\varepsilon_{i j k}$

$\mathrm{i}=1,2 \ldots \mathrm{a} ; \mathrm{j}=1,2 \ldots \mathrm{b} ; \mathrm{k}=1,2 \ldots \mathrm{r}$

Where:

- $\quad \mu$ is the overall mean response,

- $\tau_{i}$ is the effect due to the $i$-th level of factor $A$,

- $\quad \beta_{j}$ is the effect due to the $j$-th level of factor $B$ and

$\gamma_{\mathrm{ij}}$ is the effect due to any interaction between the i-th level of $\mathrm{A}$ and the $\mathrm{j}$-th level of $\mathrm{B}$.

Due to any interaction between the i-th level of $\mathrm{A}$ and the $\mathrm{j}$-th level of B. [1]

A.2.Fixed factors and effects models

We consider the levels of factor A and B chosen for the experiment to be the only levels of interest in the experimenter. The factors A and B are said to be fixed factors and the model is a fixed-effects model. When an AxB factorial experiment is conducted with an equal number of observations per treatment combination, the total (corrected) sum of squares is partitioned as:

$\mathrm{SS}_{(\text {total }}=\mathrm{SS}_{(\mathrm{A})}+\mathrm{SS}_{(\mathrm{B})}+\mathrm{SS}_{(\mathrm{AB})}+\mathrm{SS}_{\mathrm{E}}$

Where: $\mathrm{AB}$ represents the interaction between $\mathrm{A}$ and $\mathrm{B}$. For reference, the formulas for the sums of squares are:

$\mathrm{SS}_{\mathrm{A}}=\mathrm{r}_{\mathrm{b}} \sum_{\mathrm{i}=1}^{\mathrm{a}}\left(\overline{\mathrm{y}}_{\mathrm{i}}-\overline{\mathrm{y}}\right)^{2}$

$\mathrm{SS}_{\mathrm{B}}=\mathrm{r}_{\mathrm{a}} \sum_{\mathrm{i}=1}^{\mathrm{b}}\left(\overline{\mathrm{y}}_{\mathrm{i}}-\overline{\mathrm{y}}\right)^{2}$

$\mathrm{SS}_{\mathrm{AB}}=\mathrm{r} \quad \sum_{\mathrm{j}=1}^{\mathrm{b}} \sum_{\mathrm{i}=1}^{\mathrm{a}}\left(\overline{\mathrm{y}}_{\mathrm{ij}}-\overline{\mathrm{y}}_{\mathrm{i}}-\overline{\mathrm{y}}_{\mathrm{l}}+\overline{\mathrm{y}}\right)^{2}$

$\mathrm{SS}_{\mathrm{E}}=\sum_{\mathrm{k}=1}^{\mathrm{r}} \sum_{\mathrm{j}=1}^{\mathrm{b}} \sum_{\mathrm{i}=1}^{\mathrm{a}}\left(\mathrm{y}_{\mathrm{ijk}}-\overline{\mathrm{y}}_{\mathrm{ij}}\right)^{2}$

C.3.The breakdown of the total corrected of mean sums squares 
The table ANOVA result can be used to test hypotheses about the effects and interactions. The table (I) shows the resulting ANOVA for $\mathrm{an} \mathrm{a} \times \mathrm{b}$ factorial experiment.

Table 1: Anova Result for an A X B Factorial Experiment

\begin{tabular}{|c|c|c|c|c|}
\hline Source & SS & Df & MS & $\mathrm{F}$ \\
\hline Factor A & $\mathrm{SS}_{(\mathrm{A})}$ & $(\mathrm{a}-1)$ & $\begin{array}{l}\mathrm{MS}_{(\mathrm{A})}= \\
\mathrm{SS}_{(\mathrm{A})} /(\mathrm{a}-1)\end{array}$ & $\mathrm{F}=\mathrm{MS}_{\mathrm{A}} / \mathrm{MS}_{\mathrm{E}}$ \\
\hline $\begin{array}{l}\text { Factor } \\
\text { B }\end{array}$ & $\mathrm{SS}_{(\mathrm{B})}$ & (b-1) & $\begin{array}{l}\mathrm{MS}_{(\mathrm{B})}= \\
\mathrm{SS}_{(\mathrm{B})} /(\mathrm{b}-1)\end{array}$ & $\mathrm{F}=\mathrm{MS}_{\mathrm{B}} / \mathrm{MS}_{\mathrm{E}}$ \\
\hline Interaction $\mathrm{AB}$ & $\mathrm{SS}_{(\mathrm{AB})}$ & $\begin{array}{l}(a-1)^{*}(b- \\
1)\end{array}$ & $\begin{array}{l}\mathrm{MS}_{(\mathrm{AB})}= \\
\mathrm{SS}_{(\mathrm{AB})} /(\mathrm{a}- \\
1) \\
\text { (b-1) }\end{array}$ & $\begin{array}{l}\mathrm{F}=\mathrm{MS}_{\mathrm{AB}} / \mathrm{MS}_{\mathrm{E}} \\
=\mathrm{SS}_{\mathrm{AB}} /(\mathrm{a}-1)^{*}(\mathrm{~b}- \\
1)\end{array}$ \\
\hline Error & SSE & $(n-a b)$ & $\begin{array}{l}\mathrm{MS}_{\mathrm{E}}= \\
\mathrm{SS}_{\mathrm{E}} /(\mathrm{n}- \\
\mathrm{ab})\end{array}$ & \\
\hline $\begin{array}{l}\text { Total (Corr- } \\
\text { ected) }\end{array}$ & $\begin{array}{l}\text { SS } \\
\text { (To- } \\
\text { tal) }\end{array}$ & $(\mathrm{n}-1)$ & & \\
\hline
\end{tabular}

\section{Experimental}

\subsection{Algorithm}

In this part, we use a general algorithm which can let us applied the defined methods in image treatment.

- We read a pathological and normal images with format "Dicom".

- We apply ANOVA 1 way.

- We apply ANOVA2 ways.

- We compare between the both techniques in order to achieve the best technique that gives the best accuracy time for surface detection in multi images.

For the test, we have used a computer which has these identifications:

- Model: SONY (RSOL-VAIO)

- Processor: Intel(R) core ${ }^{\mathrm{TM}} \mathrm{i} 5-3210 \mathrm{M} . \mathrm{CPU} @ 2.55 \mathrm{GHz}$

- Memory (RAM): 4.00 Go.

- Operating system: windows 7_64bits.

- Matlab® 13 (R2013a).

Let's explain in more detail:

The anatomical model used to generate simulated brain MRI data consist of a set of 3-dimensional "fuzzy" tissue membership volumes, one for each tissue class (white matter, grey matter, cerebrospinal fluid, fat...). The voxel values in these volumes reflects the proportion of tissue present in that voxel, in the range $[0,1]$. The volumes are defined at a $1 \mathrm{~mm}$ isotropic voxel grid in Talairach space, with dimensions $181 \times 217 \times 181$ (XxYxZ) and start coordinates $-90,-126,-72(\mathrm{x}, \mathrm{y}, \mathrm{z})$.

In addition to the fuzzy tissue membership volumes, a discrete anatomical model is provided which consists of a Class label (integer) at each voxel, presenting the tissue which contributes the most to that voxel $(0=$ background, $1 \mathrm{CSF}, 2=$ grey matte, 3 white matter, 4=Fat, 5=muscle/skin, 6=skin, 7=skull, 8=glial matter, $9=$ connective, $10=\mathrm{MS}$ lesion).

Brain web Simulated MRI Volumes for Brain with Multiple Sclerosis Lesions select the desired simulated volume using the switches (see figure1). These simulations are based on an anatomical model of a brain with MS lesions, which can serve as the ground truth for any analysis procedure.

In this pre-computed simulated brain database (SBD), the parameter settings are fixed to 3 modalities, 5 slice thicknesses, 6 levels of noise, and 3 levels of intensity non-uniformity. You can also request simulations done with arbitrary parameters from the BrainWeb custom MRI simulations interface.

The voxel values in each image are magnitude values, rather than complex, real or imaginary.

We apply the algorithm of ANOVA1 ways in our data. The results of ANOVA1 techniques for multi-frames are shown in figure4, and the duration of execution time is shown in figure5.

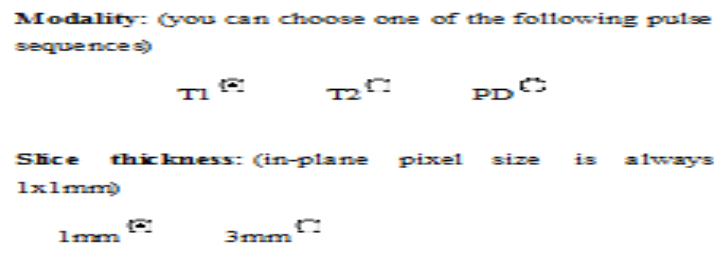

Fig. 1: Switches for Desired Simulated MRI Volume [9].

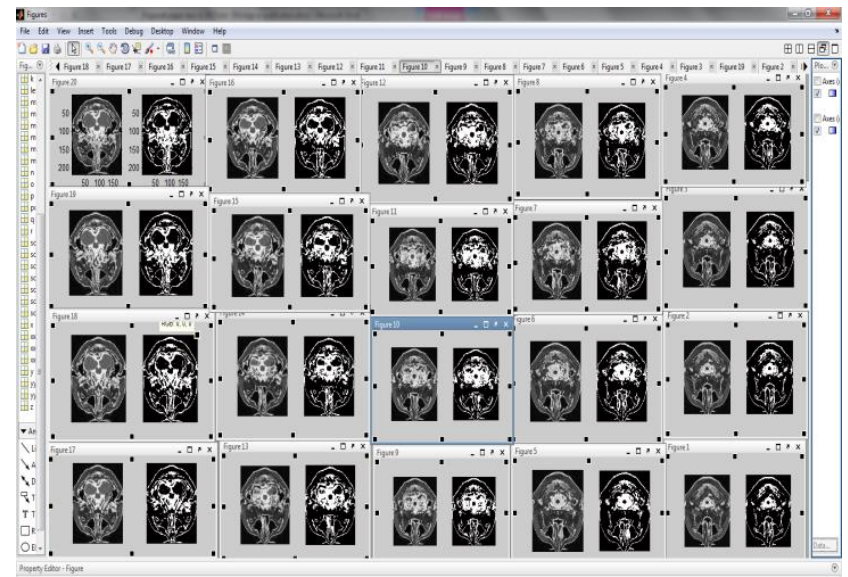

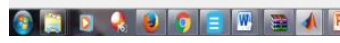

Fig. 2: Results of ANOVA 2 Techniques for Multi-Frames (20frames) in $\mathrm{T} 2$.

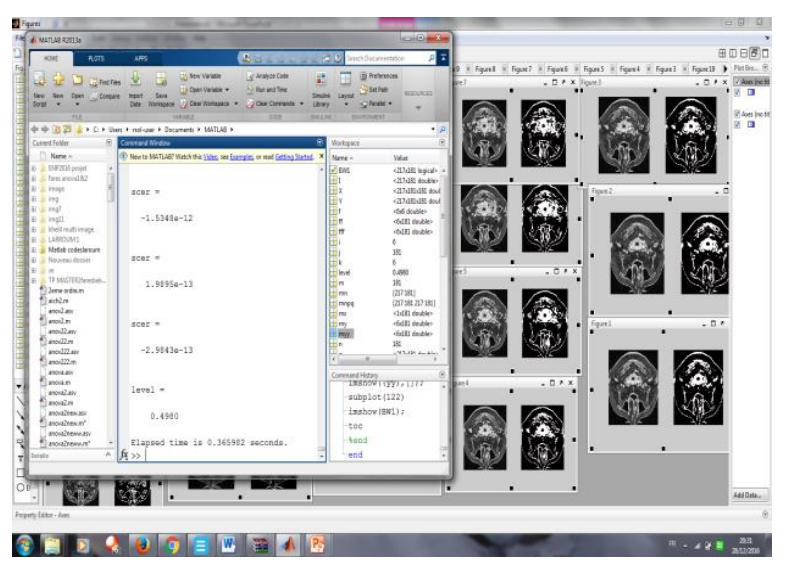

Fig. 3: Elapsed Time of ANOVA2 in $\mathrm{T} 2$ for Multi-Frame.

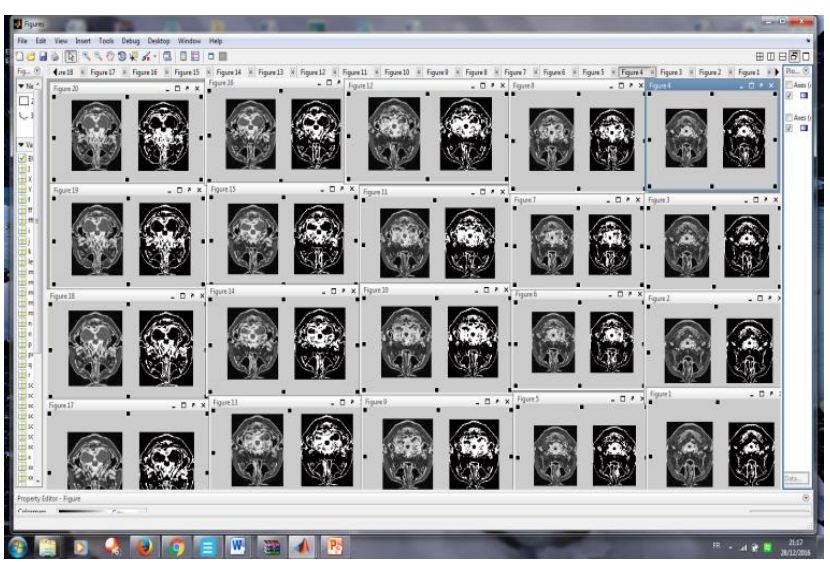

Fig. 4: Results of ANOVA 1 Techniques for Multi-Frames in T2. 


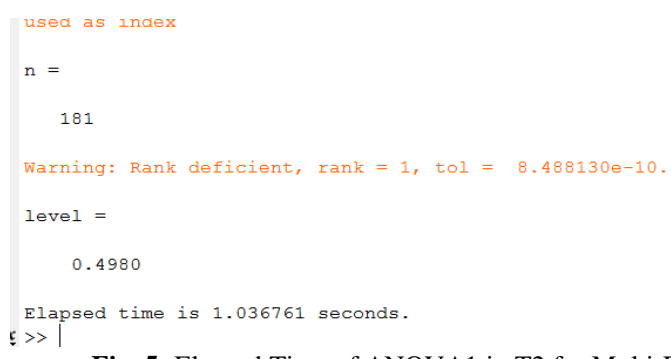

Fig. 5: Elapsed Time of ANOVA1 in T2 for Multi-Frame.

\section{Discussion}

In the both figures (2) and (4) in relaxing time T2 Anova1 and Abova2 detect the disease in the same precision but with accuracy in ANOVA2 (0.36s) in front of ANOVA1(1.036s).see figures and (3)( 5$)$.

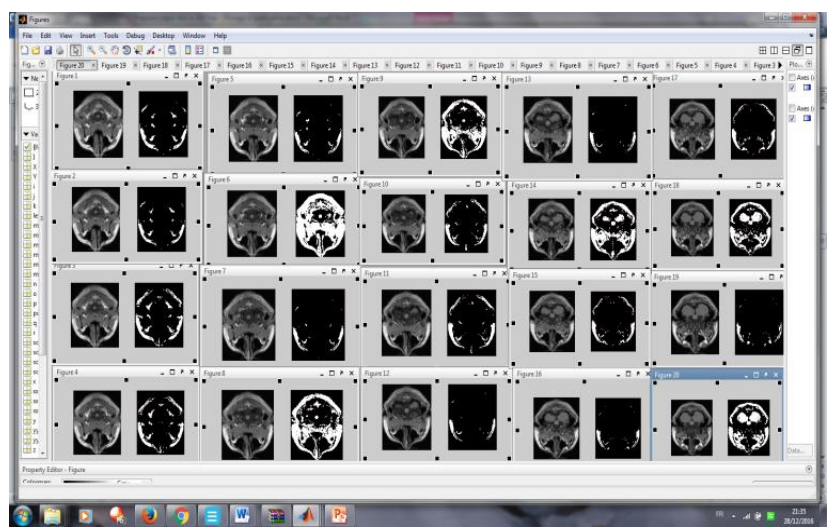

Fig. 6: Results of ANOVA 2 Techniques for Multi-Frames in T1.

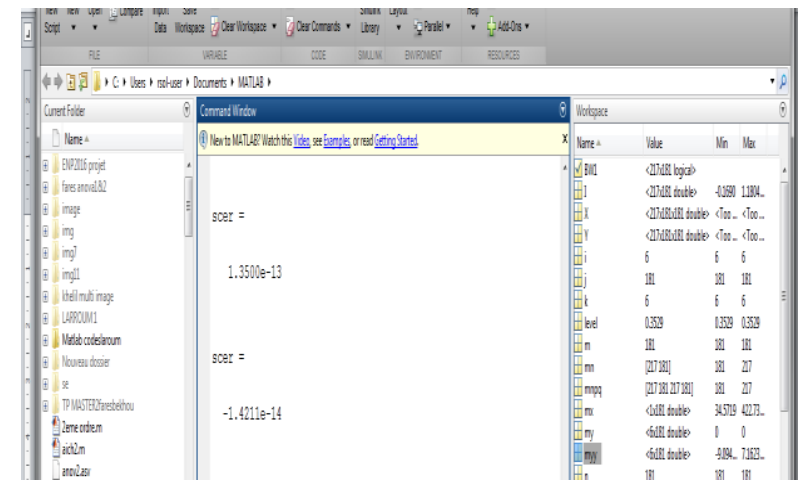

Fig. 7: Elapsed Time for ANOVA2 Int1.

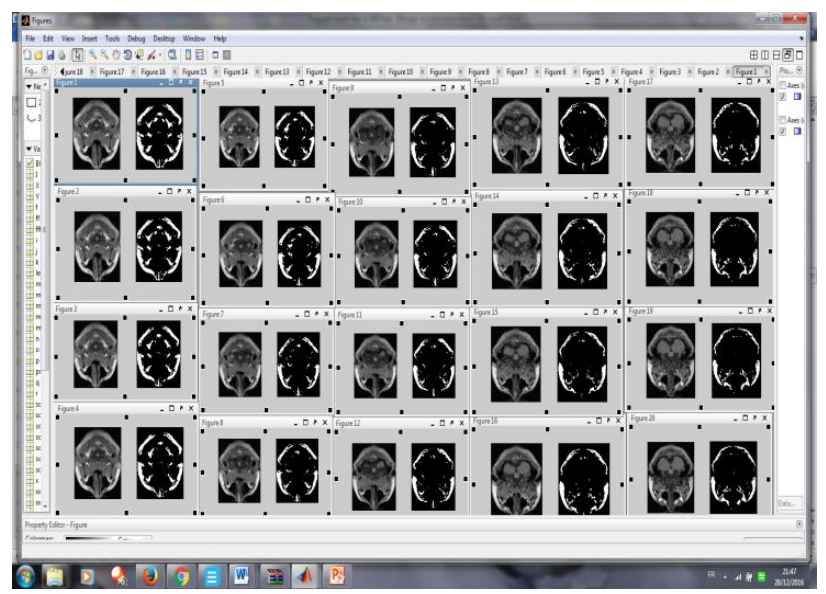

Fig. 8: Detection Multi-Images Int1 for ANOVA1.

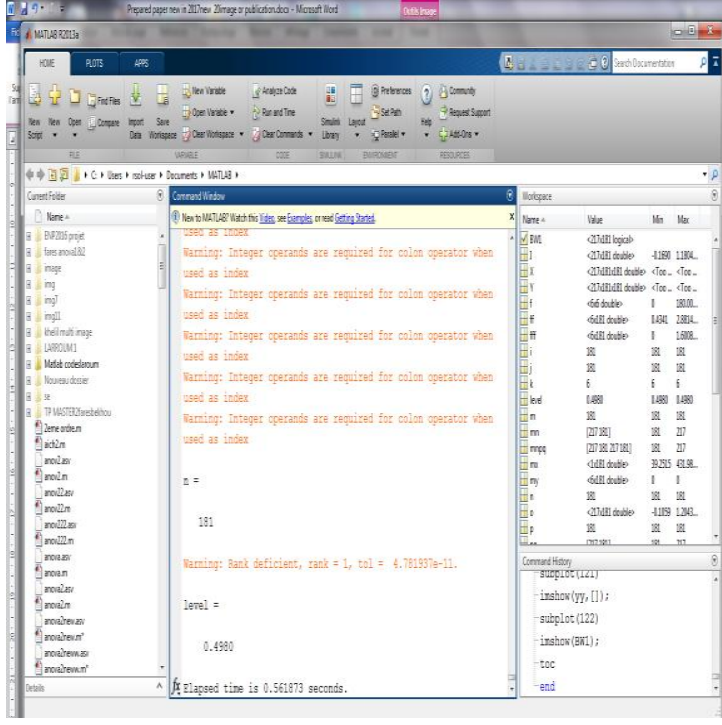

Fig. 9: Time of Execution of ANOVA1 in T1.

We apply the algorithm on 20 images compressed with mnc (image dicom) detected with ANOVA 2 for time: T1. The results of ANOVA 2 techniques for multi-frames are shown in figure6, and the duration of execution time is shown in figure7.

We apply the algorithm on 20 images compressed with mnc (image dicom) detected with ANOVA 1for time: T1. The results of ANOVA1 techniques for multi-frames are shown in figure8, and the duration of execution time is shown in figure9.

\section{Discussion}

In the time T1 \& from the both figures (6) and (8) ANOVA2 detect frames better and with accuracy 0.35 seconds (figure8.) in front of ANOVA1 0.56second (figure9.) where its result is worse.

\section{Conclusion}

In this paper, we have applied two linear resolution methods to extract the place of diseases for MR images .Our results indicate that the statistical method with Anova2 converges to the solution in accuracy time in comparison with the ANOVA1 way where it couldn't detect well frames with relaxation time T1.

So the time of execution is very important to clarify the best method of detection.

As perspective we proposed to compeer Anova with network ANN.

\section{References}

[1] http://keydifferences.com/difference-between-one-way-and-twoway-anova.html

[2] http://www.itl.nist.gov/div898/handbook/prc/section4/prc4.m

[3] Frank E.Harrell, Jr, Regression modelin strategies (with applications to linear models, logistic \&ordinal regression,\& survival analysis), 2end edition, Department of biostatistics, school of medicine Vanderbilt university Nashville, TN.USA, ISSN01727397,springer series in statistics, ISBN 978-3-319-1942-0,2001

[4] Keith R.Muller Bethel A.Fetterman, Regression \&Anova, USA, 2002, ISBN 1-58025-890-5

[5] R.Henson(1) and W.Penny(2),ANOVAs and SPM, Institute of Cognitive Neuroscence, Wellcome department of enImagingNeurscence,UniversityColle geLondon.July12,(2005)

[6] Laure Tabary. Nicholas Ayache. Jacques Darcourt. Grégoire Malandain .Analyse statistique d'images médicales: étude et utilisation du logiciel SPM. Marie. (1999)

[7] Olive Jean Dunn, Virginia A. Clark, Applied Statistics: Analysis of Variance and Regression, Journal of Educational Statistics, Vol. 15, No. 2 (summer, 1990), pp. 175-178. https://doi.org/10.2307/1164769. 